\title{
Governmental Information Resources Management Base on metadata
}

\author{
Zhen Long $\mathrm{Li}^{1}$, Xiao Ming Zhao ${ }^{12}$ \\ 1 Computer Science Department, Taizhou University, Linhai, P.R. C \\ li_zhenlong@163.com. \\ 2 Information engineering institute, zhejiang Industrial University, \\ Hangzhou 310014, P.R. China \\ tzxyzxm@yahoo.com.cn
}

\begin{abstract}
The current popular methods of organizing and searching of governmental information resources was analyzed under the circumstance of building Practical e-government integrating website, in this paper, and its metadata was also discussed. In order to solve the problem of information segregate, the framework of e-governmental information resources management was proposed by using metadata. Furthermore, a prototype of governmental information resources registration and directory service system has been developed.
\end{abstract}

\section{Introduction}

All around the world, e-government is revolutionizing the concept of how government works and the quality of the services it delivers. Its essence is that the government use the information technology to transform tradition centralized management system and the multilayer operating structure in order to meets the digitized society's need [1].

With the development of society, governmental function will gradually transform from management to the service [2]. This trend makes the relative isolation management system to be changed and thereafter cooperation among government department to be realized fully. This should be done through the resources integration and realization of the cross region, cross department and concurrent government affairs processing.

However, at present the majority design of government website take the governmental function as the center. It is difficult to provide the cross department and integrated service for the social publics, as shown in the Fig.10. Because the 
information resource and business processes are separated by the function organization, "isolated Information Island" was produced, as a result of which the publics not only needs to know what they want to do (e.g., apply for business license), but also needs to know which department have the function which they wanted to utilize (e.g., commerce bureau, police station and tax affairs department etc). For the solution of question, they have to jump form one government department website to another. Meanwhile, the information which they filled in one department is usually unable to share with other ones.

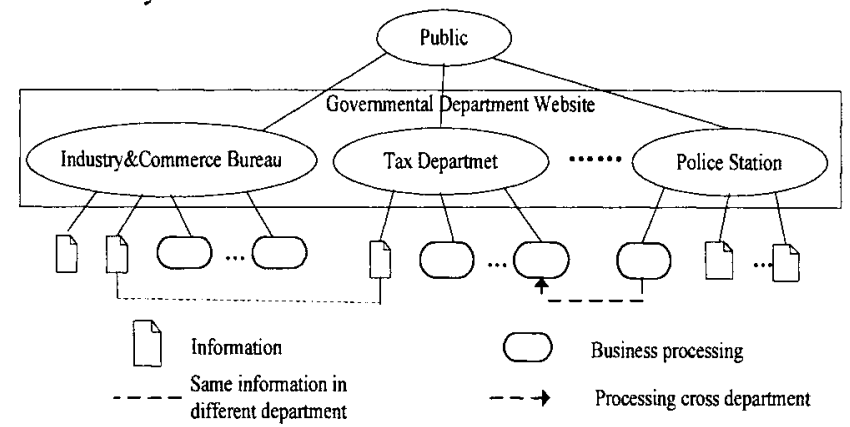

Fig. 1. Government department centered E-government system model.

\section{Our Objective}

Facing the massive separate government information resources, on the one hand, the government must research the technical means to organizes, control and manage information resource so as to provides the high efficiency and quality information service under the network environment. On the other hand, the users have to find the method to overcome the barrier which the multilayer of governmental structure lead up to them, and also to discover, obtain the valuable government information, it has become the very important issue to design the standard for the standardization description of government information resource, to realize the highly efficiency management using description standard, and to develop the new retrieval mechanism for the discovery and gain of government information resource.

In this paper, a service frame was proposed, in which the public convenience had been sufficiently considered and one-stop services were supplied, as shown in the Fig. 2. It has realized retrieval and management of government information resource in terms of the metadata and directory technology. It broke the information separation among government departments, supplied with integrated information resource and integrated information service, linked up the workflow between cooperative departments for the publics. 


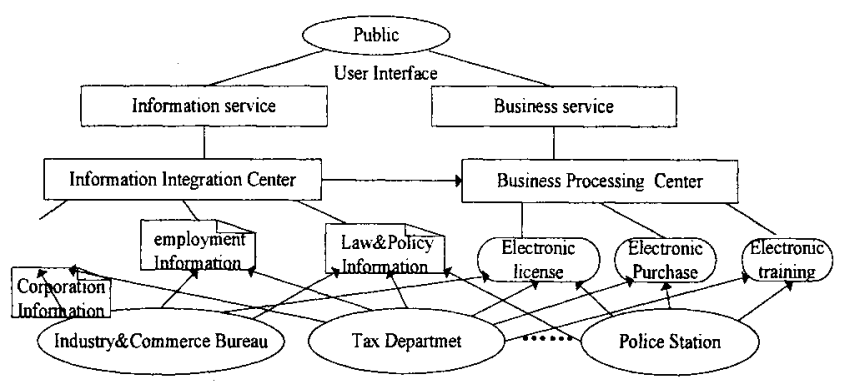

Fig. 2. public centered E-government system frame

\section{The standard description of government information resource}

In order to realize the integrated management and service of e-government information, we must find the method for the uniform description of information resource firstly. We here adopted the metadata technology for this purpose.

\subsection{Metadata concept}

The concept of metadata was first proposed by Myers in 1960. Its English meaning was interpreted as "structured data about data", also as "data which describes attributes of a resource" or as "information about data". Therefore, the metadata is called as structure data about the data content, quality, condition and other characteristic description data.

The metadata is one organizing way of information [3]; it not only offers a standardized method about information expression, but also provides a standard for definition, operation, exchange and the analysis of content in various levels of the information system as well as a tool for the computer intelligence recognition, processing, integration of information content, process and the system.

Because of unique characteristics with decentralization, changeability and multimode of the electronic information, the metadata have aroused more widespread concerns in publics. One of important research contents on metadata is the data description and the data management under the network environment.

\subsection{Metadata expression of governmental information resource}

The e-government information resource is those information which be used in the processing course of government affairs under the network environment[4]. It mainly includes the government decision information, the service information for the society, the feedback information and the intergovernmental exchange information.

At present the e-government metadata standard mainly has two systems. One is the standard which was developed by taking Dublin Core [5] as foundation, and another is the standard which was developed by taking American GILS (Government Information Locater Service) [6] as the foundation. 
The metadata, according to its concrete function, generally can be divided into intellectual metadata, access control metadata and structural metadata and so on.

- Intellectual metadata: describe the principal part and the content characteristic of the information resource. It can be used as a tool for describing, discovering and distinguishing digital information object.

- Access control metadata: describe the usable condition, and deadline, intellectual property rights characteristic and usage jurisdiction of the digital information resource.

- Structural metadata: describe internal structure of the digital information resource.

Under the circumstance of construction of the local government affairs integrated website, we had constructed a metadata standard expression mode by referring to two standards mentioned above, as shown in the table 1.

In order to realize retrieval in the directory service according to the subject, profession and region, we pay attention to the attribute marked with bold words. For example, "Publisher" be used to point out the information resource URL, "Coverage" be used to point out administrative area ruled by document creators.

Table 1. Metadata and definition

\begin{tabular}{l|l}
\hline Term name & Definition \\
\hline Title & A name given to the resource. \\
Creator & An entity primarily responsible for making the resource \\
subject & The topic of the resource. \\
Description & An account of the resource \\
Publisher & An entity responsible for making the resource available \\
Contributor & An entity responsible for making contributions to the resource. \\
Date & A point or period of time associated with an event in the lifecycle of the \\
& resource \\
Type & The nature or genre of the resource \\
format & The file format, physical medium, or dimensions of the resource \\
Identifier & An unambiguous reference to the resource within a given context \\
Source & The resource from which the described resource is derived \\
Language & A language of the resource \\
Relation & A related resource \\
Coverage & The spatial or temporal topic of the resource, the spatial applicability of the \\
resource, or the jurisdiction under which the resource is relevant
\end{tabular}

\section{E-government information management Based on metadata}

\subsection{The search way of E-government information resource}

Under the current e-government environment, the user has two basic ways to search and use the government information resource.

The first way: visiting related government website according to the government function. Because the government department mostly performs specific functions which had decided the content and property of the information resource in its website, 
the user may directly visit the related government website. if you, for instance, want to search the American education information, you may login the website of the American Ministry of Education (http://www.ed.gov). Similarly, one wants to search the Chinese law information, may land website of the Supreme people's Procuratorate of the People's Republic of China (http://www.spp.gov.cn) or website of the Supreme Court of the People's Republic of China (http://www.count.gov.cn). it is apparent fact that the information user must know the government function and its URL.

The second way: using the search engine tool. The search engine is an essential method to retrieves the information on internet. It is suitable for three kinds of situation: Firstly, One need visit some government website in order to know the related information, but unable to know the URL of this government website. Secondly, one has guessed the possible publisher of information, but unable to know for certain whether this information appeared in this government website. Next, one has known the specific names of some government information, and wants to search further its concrete content, but unable to know for certain its drawer and publisher.

With the exponential increase of WWW information, search engine technology based on robot has not been able to guarantee its recall and the accuracy. Therefore, it can not satisfy the people needs of searching government information resource at all.

\subsection{Classified organization of e-government information resource}

In order to satisfy user inquiry, we classified government information according to the category attribute in metadata. The information that has some common attributes is combined together, and establishes the directory separately.

The establishment of classification system is advantageous to realize the gathering, management, service, and sharing of government information resource, and to strengthen the protection and development of government information resource.

(1) The subject classification: classify according to the content of government information resources;

(2) The profession classification: according to the profession domain information of government information resource;

(3) The region classification: classify level by level according to the locus of creator of government information resource;

After classification, we may construct the service platform of government information resource in order to provide the many kinds of directory retrieval ways for the user.

\subsection{The registration and directory service system based on metadata}

The directory technology is refers to the technology of information resource classification, directory constitution, structure, storage, inquiry and so on [7].

The metadata has provided the structured description method of government information resource, so the metadata database can be established through metadata 
registration. Thereafter, the management, discovery and exchange system of government information resource can be developed using directory technology.

Using directory and metadata technology, we have constructed registration and directory service system of government information resource. Its overall frame as shown in the Fig. 3.

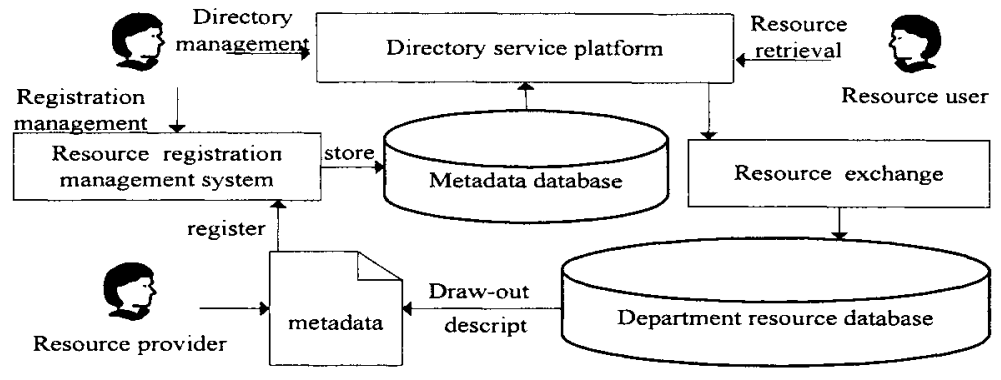

Fig. 3. Registration \&directory service system of government information resources

There are resources provider, registration manager and resources user in the registration system. They deal with the resources submitting, resources registration management and the resources retrieval separately. Resources provider gathers the information resource from local department system, then catalog to form metadata which describe the resources. The registration manager will accept the metadata that come from resources provider and store it in the metadata database, then provides the searching service by create the resources directory using directory service platform. In the end, the resources user may query information using the directory service platform of the government information resource.

\section{Conclusion}

This research, under the circumstance of building effective local e-government integrated website, has developed the registration management and directory service system of the government information resources base on the metadata. The system already realized the retrieval of data resources and access of service through an integrated website. The service integration needs to be further studied. In the course of the system development, we realized deeply that in order to promote scaling property of the system, it is most important to make unified metadata standard referring to the division of national administrative area and the division of national economy profession.

\section{Acknowledgements}

The research was funded by the National Natural Science Foundation of China (No. 60473024) and by Zhejiang Province natural science foundation project (No.M603009). 


\section{References}

1. W.L. Scherlis and J. Eisenberg, IT Research Innovation and E-Government. Communication of ACM 2003, 45(1), pp. 67-68.

2. C. Steven, E. William, The Future of E-Government, A Project of Potential Trends And Issues. Proceedings of The 36th Hawaii International Conference on System Sciences, 2003, pp.1-146.

3. L. Xiao, X.Y. Feng and Y.Y. Shen, Study of Structure and Extended Rules in Descriptive Metada, Digital library, 2004 (9), pp. 5-8.

4. H.C. Liu, Research on the Exploitation Tactics of E-government I Books Information Knowledge nformation Resources, 2005(4), pp. 58-62.

5. Global Information Locator Service (GILS) (May 31, 2005); http://www.gils.net/.

6. Dublin Core Metadata Initiative (DCMI) (December 18, 2006); http://dublincore.org/

7. T. Roland and W. Maria, Directions in E-Government: Processes Portals, Knowledge Proceedings of The 12th International Workshop on Database And Expert Systems Applications, IEEE Computer Society, 2001, pp. $313-317$. 